\section{Anesthetic Efficacy in Irreversible Pulpitis: A Randomized Clinical Trial}

\author{
Carlos E. Allegretti ${ }^{1}$, Roberta M. Sampaio ${ }^{2}$, Anna C. R. T. Horliana ${ }^{3}$, Paschoal
}

L. Armonia ${ }^{1}$, Rodney G. Rocha ${ }^{2}$, Isabel Peixoto Tortamano ${ }^{2}$

\author{
'Institute of Health Sciences, \\ UNIP - Universidade Paulista, \\ São Paulo, SP, Brazil \\ ${ }^{2}$ Department of Stomatology, Dental \\ School, USP - Universidade de \\ São Paulo, São Paulo, SP, Brazil \\ ${ }^{3}$ Department of Health, \\ UNINOVE - Universidade Nove \\ de Julho, São Paulo, SP, \\ Brazil
}

Correspondence: Dr. 1sabel Peixoto Tortamano, Avenida. Prof Lineu Prestes, 2227 - Cidade Universitária - 05508-900 São Paulo, SP, Brasil. Tel: +55-11-3091-7813. e-mail: iptortam@usp.br

\begin{abstract}
Inferior alveolar nerve block has a high failure rate in the treatment of mandibular posterior teeth with irreversible pulpitis. The aim of this study was to compare the anesthetic efficacy of 4\% articaine, $2 \%$ lidocaine and 2\% mepivacaine, all in combination with 1:100,000 epinephrine, in patients with irreversible pulpitis of permanent mandibular molars during a pulpectomy procedure. Sixty-six volunteers from the Emergency Center of the School of Dentistry, University of São Paulo, randomly received $3.6 \mathrm{~mL}$ of local anesthetic as a conventional inferior alveolar nerve block (IANB). The subjective signal of lip numbness, pulpal anesthesia and absence of pain during the pulpectomy procedure were evaluated respectively, by questioning the patient, stimulation using an electric pulp tester and a verbal analogue scale. All patients reported the subjective signal of lip numbness. Regarding pulpal anesthesia success as measured with the pulp tester, the success rate was respectively $68.2 \%$ for mepivacaine, $63.6 \%$ for articaine and $63.6 \%$ for lidocaine. Regarding patients who reported no pain or mild pain during the pulpectomy, the success rate was, respectively $72.7 \%$ for mepivacaine, $63.6 \%$ for articaine and $54.5 \%$ for lidocaine. These differences were not statistically significant. Neither of the solutions resulted in $100 \%$ anesthetic success in patients with irreversible pulpitis of mandibular molars.
\end{abstract}

\section{Introduction}

Conventional inferior alveolar nerve block (IANB) is the most commonly used technique for achieving pulpal anesthesia in posterior mandibular endodontic procedures (1-3). However, IANB has a high failure rate $(1,3)$ and success rates are even lower when applied for the treatment of mandibular posterior teeth with irreversible pulpitis (1,3-6).

Various clinical studies have attempted to resolve the shortcomings of IANB in patients with irreversible pulpitis. These reports have generally compared local anesthetic solutions to lidocaine (2,5-6), which is currently considered the most frequently used anesthetic in dentistry and can be considered as the "gold standard," i.e., the drug to which all local anesthetics are compared (7).

Other local anesthetic agents, such as articaine, bupivacaine and mepivacaine, are also available commercially (3). Articaine was recently introduced to the market and has been extensively studied because of its distinctive molecular characteristics that provide increased liposolubility (8). However, some authors have shown that there is no difference between $2 \%$ lidocaine and $4 \%$ articaine, both in combination with 1:100,000 epinephrine, in IANB in patients with irreversible pulpitis $(2,5)$. A recent systematic review and meta-analysis concluded that there is a significant advantage when using articaine over lidocaine for supplementary infiltration after mandibular block anesthesia, but no advantage when used for mandibular block anesthesia alone or for maxillary infiltration (9).

A single study in the literature evaluated mepivacaine at 3\% without a vasoconstrictor in IANB in patients with irreversible pulpitis and mepivacaine proved to be as effective as 2\% lidocaine with 1:100,000 epinephrine in achieving pulpal anesthesia of mandibular molars (1). A meta-analysis of randomized controlled trials about the efficacy and safety of mepivacaine, compared with lidocaine when used in local anaesthesia in dentistry concluded that $2 \%$ mepivacaine with vasoconstrictors is better than $2 \%$ lidocaine with vasoconstrictors in dental treatment (10). However, to the best of authors' knowledge, no studies have compared mepivacaine and lidocaine at this same concentration (2\%), both associated with the same 1:100,000 dose of epinephrine in IANB in patients with irreversible pulpitis

Therefore, the aim of this study was to compare the anesthetic efficacy of $4 \%$ articaine, $2 \%$ lidocaine and $2 \%$ mepivacaine, all in combination with 1:100,000 epinephrine, in the conventional IANB in patients with mandibular molars with irreversible pulpitis. The null hypothesis tested was that there is no difference in the anesthetic efficacy among the three anesthetic solutions.

\section{Material and Methods}

The study adhered to the Helsinki Declaration of 1975 as revised in 2000 and 2008 (11). Each patient was aware and asked to provide written informed consent. The study was approved by the Committee for Ethics in Human Research of the Dental School, University of São Paulo (protocol $112 / 2010$ ) and was recorded in clinicaltrials.gov with the 
name of "Anesthetic Efficacy in Irreversible Pulpitis" (NTC ID:NCT02054767).

Sixty-six adult patients $(n=66)$ participated in this prospective, randomized, double-blind clinical study. Sample size calculation, based on type I error of 5\% and a power of $80 \%$, indicated that at least 66 patients would be required to detect moderate ( 0.3 to 0.5 ) and large (greater than 0.5) effect sizes.

All patients were treated at the Emergency Department of the Dental School, University of São Paulo and received a clinical diagnosis of irreversible pulpitis of the first or second molars. Patients had moderate to severe spontaneous pain and exhibited a positive response to the electric pulp test and a prolonged response to cold testing with Endo-Frost (Coltène-Roeko, Langenau, Germany). For inclusion in the study, patients had to be between 18 and 50 years of age and in good health, as established by a health history questionnaire. Each participant had at least 1 adjacent molar to the tooth with irreversible pulpitis and 1 healthy contralateral canine without deep carious lesions, extensive restoration, advanced periodontal disease, history of trauma or sensitivity. Patients taking medication that could interfere with any of the anesthetics used in the $\Xi$ study were excluded.

Sixty-six patients were divided into 3 parallel groups of 22 patients each and received $3.6 \mathrm{~mL}$ injections for IANB (equivalent to 2 cartridges) of 4\% articaine (Articaine 100; DFL, Rio de Janeiro, RJ, Brazil) with 1:100,000 epinephrine, 2\% lidocaine (Alphacaine 100; DFL, Rio de Janeiro, RJ, Brazil) with 1:100,000 epinephrine or 2\% mepivacaine (Mepiadre; DFL, Rio de Janeiro, RJ, Brazil) with 1:100,000 epinephrine. To ensure a blind test, 2 cartridges $(3.6 \mathrm{~mL}$ ) of each anesthetic solution were sealed in envelopes (ACRTH). At the time of application, the researcher randomly selected 1 of the envelopes and consecutively administered the 2 anesthetic injections (IFP). Electrical stimulation of the tooth pulp (RMS) and the pulpectomy (CEA) were performed by different professionals to ensure that the anesthetic solution remained unknown, thereby maintaining the double-blind nature of the study. Two negative responses to maximal stimulation of the device $(80 \mu \mathrm{A})$ were used to determine whether the pulpal anesthesia was successful, i.e., to characterize the pulpal anesthesia.

Prior to the injections for IANB, the molar with irreversible pulpitis, the adjacent molar and the contralateral canine were tested to determine the pulp vitality using an electric pulp stimulator (Scanner Vitalidade 2006; SybronEndo, Orange, CA, USA). Electrical stimulation of the unanesthetized contralateral canine tooth pulp was used as a control to ensure that the equipment was functioning properly and that the patients were responding appropriately.
To perform the anesthetic infiltration, a carpule syringe with a 27-G 0.4 X 35-mm needle (Terumo Needle; DFL Industria e Comercio Ltda, Rio de Janeiro, RJ, Brazil) equipped with a blood aspirator attached to a ring (Konnen; Kennen Indústria e Comércio Ltda, São Paulo, SP, Brazil) was used. Blood aspiration tests were performed before each anesthetic injection as well as changes in the needle position. Both cartridges of anesthetic solution were applied following the procedure described below. In the first step of the first anesthetic ( 1 cartridge, $1.8 \mathrm{~mL}$ ), the needle was inserted to a depth of 3-5 mm, and the aspiration test was performed. If the aspiration was negative, approximately $0.3 \mathrm{~mL}$ of anesthetic solution was injected. In the second step, the syringe was directed at the bicuspid region on the opposite side and the needle was inserted until it made contact with the bone. Thereafter, the needle was withdrawn by 1-2 $\mathrm{mm}$, another aspiration test was performed and the remaining $1.5 \mathrm{~mL}$ of the anesthetic solution was slowly injected. The second anesthetic (1 cartridge, $1.8 \mathrm{~mL}$ ) was applied immediately after the second stage of the first anesthesia. The average injection time for each cartridge was approximately $2 \mathrm{~min}$.

Ten minutes after application of the IANB, lip numbness was assessed by asking the patient whether his/her lip felt numb. Right after that, the electrical stimuli tests were repeated to determine pulpal anesthesia (the duration of the tests was approximately $3 \mathrm{~min}$ ). Immediately after the electrical tests, pulpectomy was initiated, which was done 14 to 16 min after IANB. During the pulpectomy, patients were instructed to report any pain sensation. To evaluate pain intensity during the pulpectomy, the following verbal analogue scale was adopted $(5,6): 0$, no pain; 1 , mild, bearable pain; 2 , moderate, unbearable pain; and 3, severe, intense and unbearable pain. Anesthesia was considered successful when the pulp chamber was accessed without reports of unbearable pain by the patient (pain scale of 0 or 1). In these cases, the pulpectomy was performed without interruption. When the pain was classified as levels 2 or 3 , the IANB was considered as ineffective. In such cases, periodontal ligament injections or, if necessary, intrapulpal injections were made, and the pulpectomy was then performed.

Using the chi-square test, the patients' responses to the electrical test (negative or positive), the pain recorded during the pulpectomy, the distribution of the types of teeth with irreversible pulpitis (first or second molar) and the sex of the patients in the 3 different groups were compared. Possible differences in age among the 3 groups of patients were analyzed with the Kruskal-Wallis test. For all performed tests, the level for significance for differences was $p \leq 0.05$. 


\section{Results}

No patient had any adverse effect related to the administration of local anesthetics or harms related to the procedures. There were no statistically significant differences in the sex distribution (articaine group - 54.5\% female, lidocaine group - $59.1 \%$ female and mepivacaine group $-72.7 \%$ female, $p=0.184$ ), age (mean age: articaine group - 28.7 years, lidocaine group - 30.3 years and mepivacaine group - 33.9 years, $p=0.147$ ) and the types of teeth with irreversible pulpitis $(p=0.654)$ among the 3 groups (Tables 1-3). Therefore, the results for the anesthetic solutions could be directly compared.

All 66 patients (100\%) reported lip numbness 10 min after receiving IANB. Prior to start the pulpectomy procedure, 14 patients (63.6\%) in the articaine group (Table

Table 1. Characteristics of patients (age, sex, type of teeth with irreversible pulpitis), the patients' responses to the electrical test after the inferior alveolar nerve block (negative or positive), the description of pain intensity $(0,1,2$ or 3$)$ and analgesia during the pulpectomy procedure in the articaine group

\begin{tabular}{|c|c|c|c|c|c|c|}
\hline Paciente & Age & Sex & Tooth & $\begin{array}{l}\text { Response } \\
\text { to pulp } \\
\text { tester }\end{array}$ & Pain & Analgesia \\
\hline 1 & 30 & M & 36 & Negative & 0 & Yes \\
\hline 2 & 47 & $\mathrm{~F}$ & 36 & Negative & 0 & Yes \\
\hline 3 & 34 & M & 37 & Negative & 0 & Yes \\
\hline 4 & 30 & M & 47 & Positive & 1 & Yes \\
\hline 5 & 18 & M & 37 & Negative & 0 & Yes \\
\hline 6 & 27 & $\mathrm{~F}$ & 46 & Negative & 0 & Yes \\
\hline 7 & 45 & $\mathrm{~F}$ & 47 & Negative & 0 & Yes \\
\hline 8 & 19 & M & 37 & Negative & 0 & Yes \\
\hline 9 & 24 & M & 37 & Negative & 0 & Yes \\
\hline 10 & 22 & M & 36 & Negative & 1 & Yes \\
\hline 11 & 36 & $\mathrm{~F}$ & 47 & Positive & 3 & No \\
\hline 12 & 24 & M & 37 & Negative & 1 & Yes \\
\hline 13 & 18 & $\mathrm{~F}$ & 36 & Negative & 2 & No \\
\hline 14 & 31 & $\mathrm{~F}$ & 46 & Positive & 2 & No \\
\hline 15 & 29 & M & 37 & Positive & 2 & No \\
\hline 16 & 39 & $\mathrm{~F}$ & 46 & Positive & 3 & No \\
\hline 17 & 30 & M & 36 & Positive & 2 & No \\
\hline 18 & 30 & $\mathrm{~F}$ & 46 & Positive & 2 & No \\
\hline 19 & 19 & M & 37 & Negative & 0 & Yes \\
\hline 20 & 32 & $\mathrm{~F}$ & 46 & Positive & 2 & No \\
\hline 21 & 23 & M & 47 & Negative & 0 & Yes \\
\hline 22 & 24 & $\mathrm{~F}$ & 47 & Negative & 0 & Yes \\
\hline
\end{tabular}

1), 14 patients $(63.6 \%)$ in the lidocaine group (Table 2) and 15 patients $(68.2 \%)$ in the mepivacaine group (Table 3) demonstrated pulpal anesthesia (negative response to maximum stimulation of $80 \mu \mathrm{A}$ generated with an electric pulp stimulator). This difference between groups was not statistically significant ( $p=0.935$ ) (Fig. 1). During the pulpectomy, 8 patients in the articaine group (36.4\%) (Table 1), 10 patients in the lidocaine group (45.5\%) (Table 2) and 6 patients in the mepivacaine group (27.3\%) (Table 3) reported pain (a pain score of 2 and 3), but this difference among groups was not statistically significant ( $p=0.456)$ (Fig. 2).

\section{Discussion}

All patients (100\%) exhibited lip numbness. However,

Table 2. Characteristics of patients (age, sex, type of teeth with irreversible pulpitis), the patients' responses to the electrical test after the inferior alveolar nerve block (negative or positive), the description of pain intensity $(0,1,2$ or 3$)$ and analgesia during the pulpectomy procedure in the lidocaine group

\begin{tabular}{|c|c|c|c|c|c|c|}
\hline Paciente & Age & Sex & Tooth & $\begin{array}{c}\text { Response } \\
\text { to pulp } \\
\text { tester }\end{array}$ & Pain & Analgesia \\
\hline 1 & 19 & M & 36 & Positive & 0 & Yes \\
\hline 2 & 32 & $\mathrm{~F}$ & 47 & Positive & 1 & Yes \\
\hline 3 & 45 & $\mathrm{~F}$ & 36 & Negative & 0 & Yes \\
\hline 4 & 25 & $\mathrm{~F}$ & 47 & Negative & 1 & Yes \\
\hline 5 & 18 & $\mathrm{~F}$ & 36 & Negative & 0 & Yes \\
\hline
\end{tabular}

$\begin{array}{lllllll}7 & 35 & \mathrm{M} & 36 & \text { Negative } & 0 & \text { Yes }\end{array}$

$\begin{array}{lllllll}8 & 49 & \text { F } & 47 & \text { Negative } & 1 & \text { Yes }\end{array}$

$\begin{array}{lllllll}9 & 20 & \mathrm{~F} & 46 & \text { Positive } & 1 & \text { Yes }\end{array}$

$\begin{array}{llllll}10 & 23 & F & 36 & \text { Negative } 2 & \text { No }\end{array}$

$\begin{array}{llllll}11 & 19 & \mathrm{~F} & 37 & \text { Positive } & 2\end{array}$

$\begin{array}{lllllll}12 & 26 & F & 47 & \text { Negative } & 2 & \text { No }\end{array}$

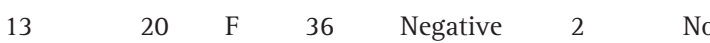

$\begin{array}{lllllll}14 & 32 & \mathrm{~F} & 37 & \text { Negative } & 0 & \text { Yes }\end{array}$

$\begin{array}{llllll}15 & 44 & F & 47 & \text { Negative } & 3\end{array}$

$\begin{array}{lllllll}16 & 38 & \mathrm{M} & 47 & \text { Negative } & 0 & \text { Yes }\end{array}$

$\begin{array}{lllllll}17 & 34 & \mathrm{M} & 46 & \text { Negative } & 2 & \text { No }\end{array}$

$\begin{array}{lllllll}18 & 31 & \mathrm{M} & 36 & \text { Positive } & 3 & \text { No }\end{array}$

$\begin{array}{lllllll}19 & 26 & \mathrm{M} & 46 & \text { Positive } & 2 & \text { No }\end{array}$

$\begin{array}{lllllll}20 & 38 & M & 37 & \text { Negative } & 0 & \text { Yes }\end{array}$

$\begin{array}{lllllll}21 & 29 & \mathrm{M} & 47 & \text { Positive } & 3 & \text { No }\end{array}$

$\begin{array}{llllll}37 & F & 47 & \text { Positive } & 3 & \text { No }\end{array}$


pulpal anesthesia was only evident in 14 patients (63.6\%) in the articaine group (Table 1), 14 patients (63.6\%) in the lidocaine group (Table 2) and 15 patients in the mepivacaine group (68.2\%) (Table 3 and Fig. 1). Thus, in agreement with previous studies $(5,6,12)$ the report of lip numbness is not an adequate indicator of pulpal anesthesia.

The results for analgesia during the pulpectomy procedure revealed that 8 patients in the articaine group (36.4\%) (Table 1), 10 patients in the lidocaine group (45.5\%) (Table 2) and 6 patients in the mepivacaine group (27.3\%) (Table 3) reported pain (Fig. 2). Among these, there was 1 patient in the articaine group (4.54\%), 5 in the lidocaine group (22.7\%) and 1 in the mepivacaine group (4.54\%) in which pulpal anesthesia was confirmed with the pulp tester (as determined by a negative response to the

Table 3. Characteristics of patients (age, sex, type of teeth with irreversible pulpitis), the patients' responses to the electrical test after the inferior alveolar nerve block (negative or positive), the description of pain intensity $(0,1,2$ or 3$)$ and analgesia during the pulpectomy procedure in the mepivacaine group

\begin{tabular}{|c|c|c|c|c|c|c|}
\hline Paciente & Age & Sex & Tooth & $\begin{array}{c}\text { Response } \\
\text { to pulp } \\
\text { tester }\end{array}$ & Pain & Analgesia \\
\hline 1 & 19 & $\mathrm{~F}$ & 46 & Negative & 0 & Yes \\
\hline 2 & 40 & F & 36 & Negative & 2 & No \\
\hline 3 & 32 & M & 36 & Negative & 1 & Yes \\
\hline 4 & 22 & $\mathrm{~F}$ & 46 & Negative & 1 & Yes \\
\hline 5 & 33 & $\mathrm{~F}$ & 37 & Positive & 1 & Yes \\
\hline 6 & 42 & M & 36 & Positive & 3 & No \\
\hline 7 & 26 & F & 36 & Negative & 0 & Yes \\
\hline 8 & 27 & F & 47 & Negative & 0 & Yes \\
\hline 9 & 38 & $\mathrm{~F}$ & 47 & Positive & 2 & No \\
\hline 10 & 26 & $\mathrm{~F}$ & 37 & Negative & 1 & Yes \\
\hline 11 & 27 & M & 46 & Negative & 1 & Yes \\
\hline 12 & 30 & $\mathrm{~F}$ & 36 & Negative & 1 & Yes \\
\hline 13 & 31 & $\mathrm{~F}$ & 37 & Negative & 1 & Yes \\
\hline 14 & 48 & $\mathrm{~F}$ & 37 & Negative & 1 & Yes \\
\hline 15 & 32 & M & 36 & Positive & 3 & No \\
\hline 16 & 50 & $\mathrm{M}$ & 47 & Negative & 1 & Yes \\
\hline 17 & 23 & M & 36 & Positive & 2 & No \\
\hline 18 & 50 & $\mathrm{~F}$ & 37 & Negative & 1 & Yes \\
\hline 19 & 33 & $\mathrm{~F}$ & 46 & Negative & 1 & Yes \\
\hline 20 & 28 & F & 36 & Positive & 3 & No \\
\hline 21 & 39 & $\mathrm{~F}$ & 46 & Positive & 1 & Yes \\
\hline 22 & 50 & $\mathrm{~F}$ & 47 & Negative & 0 & Yes \\
\hline
\end{tabular}

maximum stimulus of $80 \mu \mathrm{A})$. These results are consistent with studies by Dreven et al. (13) and other authors $(5,6)$ showing that in teeth with irreversible pulpitis, negative responses to the maximum stimulation of $80 \mu \mathrm{A}$ with an electric pulp stimulator does not clinically guarantee pulp anesthesia and thus analgesia. In contrast, pulpal anesthesia was not confirmed (as determined by a positive response to a stimulus below $80 \mu \mathrm{A})$, in 1, 3 and 2 patients in the articaine, lidocaine and mepivacaine groups, respectively, although these patients did not report pain during the pulpectomy. Similar observations were reported in the study by Sampaio et al. 2012 (6).

In the present clinical research were chosen 2 local anesthetics that have been widely tested and approved for their safety and efficacy: lidocaine and mepivacaine. In this comparison, in addition to these 2 well-established agents, were also introduced articaine, which contains a thiophene ring in its molecular structure (instead of the

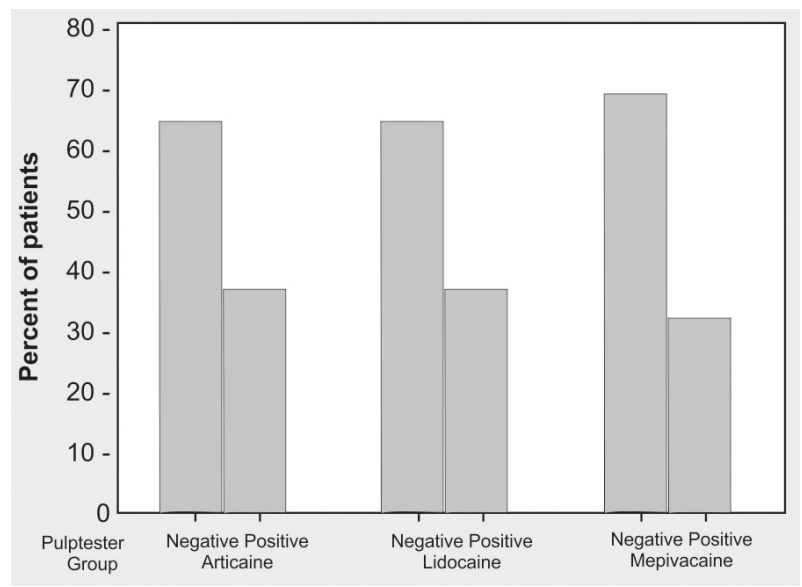

Figure 1 Pulp anesthesia. Bar graph of responses to the pulp tester (percent) after the respective IANB solutions.

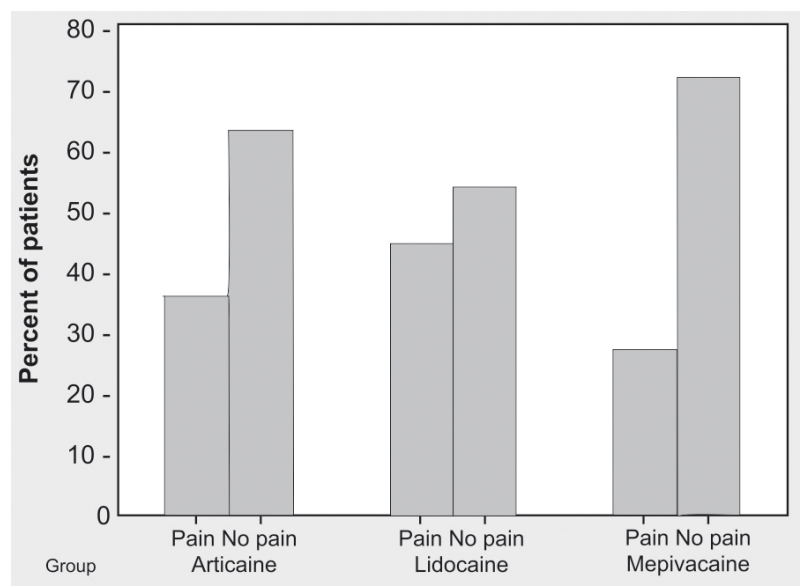

Figure 2 Analgesia. Bar graph of the occurrence of pain (percent) after the respective IANB solutions. 
typical benzene ring found in lidocaine and other amide local anesthetics) that serves to increase its liposolubility (8).

Mandibular infiltrations of articaine are believed to act as a form of regional block, due to the increase in liposolubility. Recently, Currie et al. (14) investigated a theory positing that the mentum foramen may play an important role in producing the anesthesia resulting from mandibular infiltrations, suggesting that these infiltrations achieve pulpal anesthesia by the combination of an incisive/ mentum nerve block plus local diffusion. On the other hand, Dressman et al. (15) stated that an infiltration in the region of the incisive/mental nerve, at the second premolar, was not effective enough to be recommended, even when associated with repeated infiltrations in the same area.

It is worth highlighting that both above-mentioned studies $(14,15)$ were conducted on asymptomatic teeth, and that the pulpal anesthesia was assessed using only the electric pulp tester and not confirmed by pulpectomy, as in the present study. Therefore, this agrees with Dressman et al. (15) that using solely articaine mandibular infiltrations to treat irreversible pulpitis may not be adequate. However, the authors believe that these infiltrations may be used as a complementary technique in cases when IANB is not successful in treating patients with irreversible pulpitis (16), which was confirmed in a recent systematic review (9).

Potocnik et al. (17) studied the in vitro effects of lidocaine and articaine, both at concentrations of $2 \%$ and $4 \%$, in addition to $3 \%$ mepivacaine, on decreases in the amplitude of the action potential produced by sensory nerve fibers in rats following supramaximal electrical stimulation. These authors reported that for all tested anesthetic solutions, there was complete disappearance of the action potential produced by the $\mathrm{C}$-fibers but not the A-fibers. In these experiments, $2 \%$ articaine was more effective than $2 \%$ or $4 \%$ lidocaine or $3 \%$ mepivacaine, and articaine at $4 \%$ was even more effective. However, due to the risk of accidental intravenous injection during IANB and the possibility of an incidence of paresthesia, the authors suggested replacing $4 \%$ articaine with a concentration of $2 \%$.

One of the most popular explanations for the failure of deep regional anesthesia is the presence of an infection and/or inflammation, as these conditions reduce the effectiveness of local anesthetics by reducing their bioavailability. Thus, local anesthetics with a low $\mathrm{Pk}_{\mathrm{a}}$ such as mepivacaine (3), for example, are most effective in these clinical situations (18). However, IANB involves the injection of a local anesthetic solution within the pterygomandibular space, which aims to bathe the inferior alveolar nerve before it enters the mandibular foramen (3), distant from the inflamed area.

Once again, the present study could not confirm the clinical superiority of articaine over lidocaine, which leads us to agree with Potocnik et al. (17), who suggested that factors other than the anesthetic solutions and their concentrations could be responsible for IANB failure. Other explanations that may account for IANB failures include tachyphylaxis of the anesthetic solutions (19) and activation of nociceptors, including tetrodotoxin and capsaicin-sensitive transient receptor potential vanilloid type 1 (TRPV-1) receptors $(19,20)$. In addition, one should not neglect other simple causes, such as incorrect IANB technique, which could be related to both operator error (lack of blood aspiration leading to intravascular injections) (18), as well as individual patient variations, such as: anatomic variations in the position of the mandibular foramen due to age or individual characteristics (21), bifid alveolar nerve (22), bone density (23) and accessory innervations of the lingual nerve, mylohyoid nerve and cervical plexus (19).

The limitation of this study was the final size of the sample (66 patients), driven by the rigid criteria for inclusion and exclusion, allowing detecting moderate and large effect sizes.

Given the present results and previous reports of paresthesia following the use of articaine (24), which occurs 5 times more often than following the use of lidocaine or mepivacaine (25), mepivacaine could be an alternative for IANB. In conclusion, the 3 anesthetic solutions tested did not exhibit 100\% anesthesia success for conventional IANB of the mandibular molars in patients with irreversible pulpitis.

\section{Resumo}

0 bloqueio do nervo alveolar inferior apresenta uma alta taxa de falha para o tratamento de dentes posteriores mandibulares com pulpite irreversivel. 0 objetivo deste estudo foi comparar a eficácia anestésica da articaína 4\%, lidocaína 2\% e mepivacaína 2\%, todas em combinação com epinefrina 1:100.000, em pacientes com pulpite irreversivel de molares mandibulares durante um procedimento de pulpectomia. Sessenta e seis voluntários do Centro de Emergência da Faculdade de Odontologia da Universidade de São Paulo receberam aleatoriamente $3.6 \mathrm{~mL}$ de anestésico local no bloqueio convencional do nervo alveolar inferior (BNAI). 0 sinal subjetivo de dormência do lábio, anestesia pulpar e ausência de dor durante o procedimento de pulpectomia foram, respectivamente, avaliados pelo interrogatório do paciente, usando um estimulador pulpar elétrico e uma escala analógica verbal. Todos os pacientes relataram o sinal subjetivo de dormência do lábio. Em relação ao sucesso da anestesia pulpar medido com o Pulp Tester, a taxa de sucesso foi, respectivamente, $68.2 \%$ para mepivacaina, 63,6\% para articaína e $63,6 \%$ para lidocaina. Relativamente aos pacientes que relataram nenhuma dor ou dor leve, durante a pulpectomia, a taxa de sucesso foi, respectivamente, $72.7 \%$ para mepivacaina, $63.6 \%$ para articaina e $54,5 \%$ para a lidocaina. Estas diferenças não foram estatisticamente significantes. Nenhuma das soluções resultou em 100\% de sucesso anestésico em pacientes com pulpite irreversível de molares mandibulares.

\section{References}

1. Cohen $\mathrm{HP}, \mathrm{Cha} B Y$, Spångberg LS. Endodontic anesthesia in mandibular molars: a clinical study. J Endod 1993;19:370-373. 
2. Claffey E, Reader A, Nusstein J, Beck M, Weaver J. Anesthetic efficacy of articaine for inferior alveolar nerve blocks in patients with irreversible pulpitis. J Endod 2004;30:568-571.

3. Aggarwal V, Jain A, Debipada K. Anesthetic efficacy of supplemental buccal and lingual infiltrations of articaine and lidocaine following an inferior alveolar nerve block in patients with irreversible pulpitis. J Endod 2009;35:925-929.

4. Rogers BS, Botero TM, McDonald MJ, Gardner RJ, Peters MC. Efficacy of articaine versus lidocaine as a supplemental buccal infiltration in mandibular molars with irreversible pulpitis: A prospective, randomized, double-blind study. J Endod 2014;40:753-758.

5. Tortamano IP, Siviero M, Costa CG, Buscariolo IA, Armonia PL. A comparison of the anesthetic efficacy of articaine and lidocaine in patients with irreversible pulpitis. J Endod 2009;35:165-168.

6. Sampaio RM, Carnaval TG, Lanfredi $C B$, Horliana $A C$, Rocha RG, Tortamano IP. Comparison of the anesthetic efficacy between bupivacaine and lidocaine in patients with irreversible pulpitis of mandibular molar. J Endod 2012;38:594-597.

7. Malamed SF. Handbook of Local Anesthesia. 5th ed. St Louis, MO: Mosby; 2004.

8. Malamed SF, Gagnon S, Leblanc D. Articaine hydrochloride: a study of the safety of a new amide local anesthetic. J Am Dent Assoc $2001 ; 132: 177-185$

9. Kung J, McDonagh $M$, Sedgley $C M$. Does articaine provide an advantage over lidocaine in patients with symptomatic irreversible pulpitis? A systematic review and meta-analysis. J Endod 2015;41:1784-1794.

10. Su N, Liu Y, Yang X, Shi Z, Huang Y. Efficacy and safety of mepivacaine compared with lidocaine in local anaesthesia in dentistry: a metaanalysis of randomised controlled trials. Int Dent J 2014;64:96-107.

11. William JR. The Declaration of Helsinki and public health. Bull Word Health Organ 2008;86:650-651.

12. Wali M, Drum $M$, Reader $A$, Nusstein J. Prospective, randomized singledblind study of the anesthetic efficacy of 1,8 and 3,6 milliliters of $2 \%$ lidocaine with 1:50,000 epinephrine for inferior alveolar nerve block. J Endod 2010;36:1459-1462.

13. Dreven $\amalg$, Reader A, Beck M, Meyers WJ, Weaver J. An evaluation of an electric pulp tester as a measure of analgesia in human vital teeth. J Endod 1987;13:233-238.

14. Currie CC, Meechan JG, Whitworth JM, Corbett IP. Is mandibular molar buccal infiltration a mental and incisive nerve block? A randomized controlled trial. J Endod 2013;39:439-443.
15. Dressman A S, Nustein J, Drum M, Reader A. Anesthetic efficacy of a primary articaine infiltration and a repeat articaine infiltration in the incisive/mental nerve region of mandibular premolars: a prospective, randomized single-blind study. J Endod 2013;39:313-318.

16. Kanaa MD, Witworth JM, Meechan JG. A prospective randomized trial of different supplementary local anesthetic techniques after failure of inferior alveolar nerve block in patients with irreversible pulpitis in mandibular teeth. J Endod 2012;38:421-425.

17. Potocnik I, Tomsic M, Sketelj J, Bajrovic FF. Articaine is more effective than lidocaine or mepivacaine in rat sensory nerve conduction block in vitro. J Dent Res 2006;85:162-166.

18. Milam SB, Giovannitti JA Jr. Local anesthetics in dental practice. Dent Clin North Am 1984;28:493-508.

19. Hargreaves KM, Keiser K. Local anesthetic failure in endodontics. Endod Topics 2002;1:26-39.

20. Chaudhary $P$, Martenson ME, Baumann TK. Vanilloid receptor expression and capsaicin excitation of rat dental primary afferent neurons. J Dent Res 2002;80:1518-1523.

21. Nortjé CJ, Farman AG, Grotepass FW. Variations in the normal anatomy of the inferior dental (mandibular) canal: a retrospective study of panoramic radiographs from 3612 routine dental patients. Br J Oral Surg 1977;15:55-63.

22. Grover PS, Lorton L. Bifid mandibular nerve as a possible cause of inadequate anesthesia in the mandible. J Oral and Maxillofac Surg 1983:41:177-179.

23. López $A B$, Diago MP. Failure of locoregional anesthesia in dental practice. Review of the literature. Med Oral Patol Oral Cir Bucal 2006;11:E510-513

24. Garisto GA, Gaffen AS, Lawrence HP, Tenenbaum HC, Haas DA. Occurrence of paresthesia after dental local anesthetic administration in the United States. J Am Dent Assoc 2010;141:836-844

25. Miller PA, Haas DA. Incidence of local anesthetic-induced neuropathies in Ontario from 1994 -1998. J Dent Res 2000;79: 627-627.

Received: November 25, 2015 Accepted: May 19, 2016 